\title{
Eddy measurements, coastal turbulence and statistics in the gulf of Lions
}

\author{
J. M. Redondo ${ }^{1}$, A. Matulka ${ }^{1,3}$, A. Platonov ${ }^{1,2}$, E. Sekula ${ }^{1}$, and P. Fraunie ${ }^{3}$ \\ ${ }^{1}$ Departament de Física Aplicada, Universitat Politècnica de Catalunya, Barcelona, Spain \\ ${ }^{2}$ MORINTECH, St. Petersburg, Russia \\ ${ }^{3}$ L. S. E. E. T. Universite Sud Toulon Var - CNRS, BP20132, 83957 La Garde, France
}

Received: 10 January 2011 - Accepted: 1 February 2011 - Published: 11 January 2013

Correspondence to: J. M. Redondo (redondo @ fa.upc.edu)

Published by Copernicus Publications on behalf of the European Geosciences Union.

\section{Eddy measurements, coastal turbulence and statistics in the gulf of Lions \\ J. M. Redondo}

\section{Title Page}

Abstract

Conclusions

Tables

14

4

Back

Full Screen / Esc

Printer-friendly Version

Interactive Discussion 


\section{Abstract}

The advances in radar sensors may be applied to study the flow in the Region of Fresh Water Influence (ROFI) region of the ocean. The Synthetic Aperture Radar (SAR) is a useful tool that may be used to study both marine water dynamics and its pollution.

5 Oil spills and natural slicks may be detected and processed with advanced computer techniques to reveal vortex dynamics and turbulence spectral characteristics of the complex eddy and current interaction in the ocean surface, more than 300 SAR images of the North-west Mediterranean Sea area taken between December 1996 and December 1998 were analyzed. A total of 255 eddies were detected under convenient environmental conditions and we analyzed statistically the appearance, size, shape and position of vortices in the test area. We find that the maximum size of the eddies detected near the coast is limited by the Rossby deformation radius and that there is a decrease in size in the coastal waters in the direction of the Liguro-Provenzal current with the largest eddies occurring near the cape of Rosas. Near the Rhone and Ebro 15 rivers, high discharges also contribute to eddy forcing, coastal radar measurements confirm the SAR observations. The role of submarine canyons in the vortex generation is also confirmed due to the asymmetry of their distribution with respect to the thalwegs. It is demonstrated that useful information of a geometrical nature obtained by SAR satellite images may be used to estimate relevant dynamical parameters of coastal flows.

\section{Introduction}

Synthetic Aperture Radar (SAR) data has increasingly been employed for a number of applications of specific relevance to the coastal and marine environment e.g. detection and monitoring of oil slicks, sea state, high resolution wind field, shallow water bathymetry, ship detection and pollution management (Gade and Redondo, 1999; Jolly et al., 2000). In order to exploit the satellite images in coastal regions and obtain

OSD

$10,55-81,2013$

Eddy measurements, coastal turbulence and statistics in the gulf of Lions

J. M. Redondo

\section{Title Page}

\section{Full Screen / Esc}

Printer-friendly Version

Interactive Discussion 
the maximum useful information we use scaling techniques in a statistical manner (Hu et al., 2009; Johannessen, 2000).

The Synthetic Aperture Radar SAR is an active radar which emits its energy in the centimetre frequencies range during a very short time period and it is able to receive 5 the echoes. Due to the large orbital velocity of the satellite $\left(7.5 \mathrm{~km} \mathrm{~s}^{-1}\right)$ approximately, the path of the antenna itself may be converted as a virtual antenna of a much larger size. The SAR instrument may also be installed on a plane, on a helicopter or on board a satellite. The SAR backscattering depends on the roughness of the small scale surface of the ocean. When the surface is rougher (mostly due to capillary waves in the 10 surface) the intensity of the receiving signal is stronger due to Bragg resonant dispersion (Platonov, 2002) and a white zone is observed in the image when the surface is very rough. The dark areas are visible when there is a concentration of tensioactive products such as oil. Other phenomenon which is well detected by SAR images in the sea surface is the Langmuir circulation, due to the surface particle concentration on the convergence zone between two vertical cells at sea. Algae, zoo-plankton, waste from industries and river flows, spillage from tankers, dregs at suspension, etc. accumulate on the convergence surface strips between two cells as seen in Fig. 1. It is precisely there that they form the high concentration tensioactive wakes or strips which we can observe clearly in the SAR images. Due to this phenomenon, the SAR images may detect many different oceanic dynamic meso-scale processes, such as internal waves, marine surface currents, hydrographic fronts, vortices and bathymetric characteristics of the sea bottom at coastal areas (Gade and Redondo, 1999; Joly et al., 2000; Redondo and Platonov, 2001).

This work strives to obtain a better understanding and compare several types of direct and remote sensing observations of the effects of surface wind turbulence on diffusivity and local circulation measured in the ocean-atmosphere interface. We obtain statistical information on the size and topological characteristics of eddies ad other features in the gulf of Lions, being able to compare coastal radar based in situ measurements with remote sensing satellite measurements. Here we also address the problem

OSD

10, 55-81, 2013

Eddy measurements, coastal turbulence and statistics in the gulf of Lions

J. M. Redondo

Title Page

Abstract Introduction

Conclusions

Tables

References

Figures

14

4

Back

Close

Printer-friendly Version

Interactive Discussion 
of the effects of background turbulence, eddy diffusivity and vorticity in the coastal areas.

The meteorological phenomena as cyclones, atmospheric fronts, surface wind, atmospheric internal waves and rains are also detected by the SAR images due to their

5 effect on the sea surface roughness, but because the scale of atmospheric processes is quite different to the ocean dynamics, i.e. Rossby deformation radius is more than 10 times larger, as discussed below, different spectral powers, synoptic front behaviour and other effects are distinguished and can be predicted or checked with cloud presence, meteorological visible and infrared images so it is possible to single out most of 10 the typical ocean structures, and among these the spiral vortices (Munk et al., 2000) also detected by sun glitter.

Next we describe the SAR images and the eddy size analysis, in Sect. 3 we present coastal based measurements of vortices in the Rhone river area and in Sect. 4 we show the statistical structure and topology of the detected vortices. Finally we discuss 15 the results and how turbulent diffusivity may be related to spectral eddy information and present the conclusions.

\section{Eddy sizes in the ocean surface}

In coastal flows the distance to the coast can be assumed as the largest possible eddy length scale $L$, on the other hand the smallest length scale for a 3-D vortex structure, 20 where molecular mixing takes place; Lk can be taken as Kolmogorov (local isotropic turbulence) scale so that $\mathrm{Lk}=\left(v^{3} / \varepsilon\right)^{1 / 4}$, being $v$ the kinematic viscosity and $\varepsilon$ the mean rate of turbulent kinetic energy dissipation. A good estimation of $\varepsilon$ is $1-5 \times 10^{-5} \mathrm{~cm}^{2}$ $\mathrm{s}^{-3}$ and for ocean water, the viscosity is $v=10^{-2} \mathrm{~cm}^{2} \mathrm{~s}^{-1}$, so Lk lies between $1 \mathrm{~mm}$ and $1 \mathrm{~cm}$. A similar Kolmogorov timescale, Tk is about one hundredth of a second. The 25 longest timescales are not fixed, but considering coastal flows, where the distance to the coast limits the structure of the flow, a few days would be the 2-D turbulence synoptic time scale. When the horizontal dimensions of the turbulent motion are much larger

OSD

10, 55-81, 2013

Eddy measurements, coastal turbulence and statistics in the gulf of Lions

J. M. Redondo

Title Page

Abstract Introduction

Conclusions

Tables

References

Figures

Back

Close

Printer-friendly Version

Interactive Discussion

14

4

$>$ I

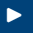

Full Screen / Esc 
than the lengthscales limited by buoyancy (e.g. Thorpe, Ozmidov, Monin-Obukhov) or by the depth of the thermocline, then large scale 2-D turbulence occurs and the vorticity axis is approximately vertical. So Kolmogorov scaling is no longer valid and a Kraichnan scaling takes place, due to a enstrophy driven cascade.

5 These features, which are ubiquitous in large scale turbulence, can be generated by circular motion due to several mechanisms: earth rotation, current shear, turbulent wind field, barotropic or baroclinic instabilities, vortexes generated by topography of the ocean bottom, etc. One of the main large scale manifestation of turbulence in the ocean (Munk et al., 2000) are synoptic eddies, which have maximum dimension of 10 around $100 \mathrm{~km}$.

In a strictly 2-D flow with weak dissipation, energy input at a given scale is transferred to larger scales, because these constraints stop vortex lines being stretched or twisted. Physically this upscale energy transfer occurs by merging of vortices and leads to the production of coherent structures in the flow. This scenario is an appropriate model 15 for geophysical flows which are known to contain very energetic vortices mesoscale oceanic eddies and atmospheric highs and lows. This upscale transfer of energy is inhibited at the Rossby deformation radius:

$R_{\mathrm{D}}=\frac{N}{f} h$.

where $h$ is the characteristic scale of the depth of the thermocline and $f$ the Coriolis parameter, $f=2 \Omega \operatorname{sen} \varphi$. The energy limitation is caused by baroclinic instability at larger scales, which accounts for the dominant observed size of geophysical vortices.

Figure 2 shows the position, the shape and the spatial direction of the 255 elliptical vortices clearly detected in the different SAR images during two years of observations. In order to better visualize the bathymetrical structure of the marine bottom, the thalwegs of the submarine canyons have been marked with lines, the technical details on the SAR images and the statistical analysis is explained in Platonov (2002).

Most of the vortices are located in a relatively nearby maritime band near to the continental shelf. It is worthwhile to note the correlation between the spatial positions of
OSD

10, 55-81, 2013

Eddy measurements, coastal turbulence and statistics in the gulf of Lions

J. M. Redondo

Title Page

Abstract Introduction

Conclusions

Tables

References

Figures

14

4

Back

Close

Printer-friendly Version

Interactive Discussion 
the vortices and the submarine canyons, most of the vortices are located towards the left side of the submarine canyons. The spatial direction of the ellipses adjusted to the vortices in the area between Rosas and the Ebro Delta was determined through the angle between the North direction and the direction of their mayor axis. The other region 5 of concentration of the vortices is situated in the centre of the marine test area. The analysis of the direction of rotation of the vortices shows that 76 have an anticyclonic character, marked in blue in Fig. 2 and 179 detected vortices correspond to cyclonic (anticlockwise) marked in red, this asymmetry was also detected by Arnau (2000); Flexas et al. $(2004,2005)$.

\section{Velocity measurements from coastal radar}

WERA HF radar technology was recently used in the eastern part of the Gulf of Lions (Reffray et al., 2004; Schaeffer et al., 2010) coordinating resources from UPC and Toulon university that allowed to point out the occurrence of an anticyclone eddy confined on the area near the Rhone estuary at the narrow shelf. Such a dominant vortex 15 feature was observed several times during winters 2005 and 2006 with a persistence of several days (i.e. Fig. 3). Process oriented modeling exercises allowed to relate the eddy formation to the wind forcing and local complex bathymetry. Different mechanisms have been described, able to induce the occurrence of such mesoscale eddies as related either to the instability of the Northern shelf edge current or to the wind forcing 20 (Schaeffer et al., 2010). In both cases, bathymetry and the Rhone river plume front play a dominant role in the confinement of the eddy. In particular, inertial motion due to wind reversal is often responsible of anticyclonic vortex formation in the water column which can be masked at sea surface by an upwelling motion. This mechanism is also believed to act in the Ebro river plume area as discussed in Carrillo et al. $(2001,2008)$, and may be seen in Fig. 1.

Integrated ROFI measurements and satellite observations have been used to simulate numerically the velocity patterns under similar conditions on selected dates.
OSD

$10,55-81,2013$

Eddy measurements, coastal turbulence and statistics in the gulf of Lions

J. M. Redondo

Title Page

Abstract Introduction

Conclusions

Tables

References

Figures

14

- I

4

Back

Close

Full Screen / Esc

Printer-friendly Version

Interactive Discussion 
Moreover, a previous investigation (Reffray et al., 2004) using a factor analysis related eddy formation was able to model the vorticity in the area of the Rhône river plume due to non linear processes. Wind forcing, Liguro Provenzal shelf current and river plume fronts influence were investigated separately and in the end, the non linear effects and 5 the modeled turbulent diffusivity were found to be the same order of magnitude in the location of eddy formation. This was also confirmed from satellite image information and from coastal radar measurements (Fig. 4). As shown also in the work of Carrillo et al. (2008) the river plume flow is one of the key elements generating certain features as long lived eddies and affecting the local diffusivity in the area.

10 Several eddies were observed on TSM SPOT images in northerly land out-shore wind condition able to reconnect the re suspended coastal waters to the river plume, enabling offshore transport of ancient deposit in the pro-delta. In this case, secondary counter rotating vortices play also a very important role in local mixing and transport. Numerical coastal model forced by idealised northerly wind are in a surprising good 15 agreement with observations.

In the complex and varying distribution vortices in the ocean, local shear will transform slicks in the surface to align and follow the local flow so the resulting pattern tends to be spiral as shown by Munk (2000). The mixing processes at large scale produce stirring, which maintains large gradients of the tracers. But in order to mix mocular level in an irreversible fashion, the energy has to cascade to the smallest internal scales (Kolmogorov or Batchelor scales). In time the area where diffusion takes place increases and the variation of area in time may be used as a measure of the overall diffusion coefficient, what has been noticed in time sequence of the eddy distribution is the occasional energetic burst that in a couple of days destroys the existing eddy distribution, after these sudden meteorological or hydraulic driven intermittent forcing, the eddies tend to grow and decay. Thermal images of the ocean, coupled with clorophyl-colour ones are suited to describe the different forcing and time evolution (Arnau, 2000), but the effect of the cloud cover precisely hampers the study of the
OSD

$10,55-81,2013$

Eddy measurements, coastal turbulence and statistics in the gulf of Lions

J. M. Redondo

\section{Title Page}


most active forcing periods. SAR images on the other hand are not affected by clouds or bad weather and the obtained eddy statistics have no weather related bias.

\section{Structure, topology and distribution of the vortical structures}

Due to the bi-normal distribution of the vortices detected fist by Redondo and 5 Platonov (2001), we consider that there exist two main types of mechanisms related to their orientation: dynamical, due to the influence of the Liguro-Provenzal current (about $50 \%$ of the detected vortexes have direction angles between $25^{\circ}$ and $75^{\circ}$, as seen in Fig. 5; and bathymetrical, due to the influence of the submarine canyons situated mostly perpendicularly to the coast line $(25 \%$ of the cases the detected vortices have azimuth angles between $125^{\circ}$ and $145^{\circ}$ ). There is also a deflection of the coastal baroclinic vortices toward the sea due to a difference in depth near the coast, and this induces a shear forced by the submarine canyons transversely to the coast. In a larger area the distribution of anti cyclonic and cyclonic eddies is quite asymmetric due to the contribution of the potential vorticity and the baroclinic instability (Matulka et al., 2008)

15 as seen in Fig. 2. The extension of most of the SAR detected vortices (78\%) is less than $100 \mathrm{~km}^{2} .18 \%$ of vortices occupy an area between 100 and $600 \mathrm{~km}^{2}$ and only $4 \%$ of the vortices possess a large area between 800 and $1200 \mathrm{~km}^{2}$ (Fig. 13). About a $60 \%$ of vortices have a minor diameter of $7 \mathrm{~km}$, a $21 \%$ have one between 8 and $20 \mathrm{~km}$ and a $16 \%$ between 21 and $44 \mathrm{~km}$.

20 The largest vortices are not stable mainly due to several reasons: The stability of the vortices depends on the Rossby deformation radio $R_{\mathrm{D}}$ defined in Eg. (1) determined in terms of buoyancy parameterized through the Brunt-Väisälä frequency $N\left[\mathrm{~s}^{-1}\right]$ that characterizes vertical oscillations of a parcel of water in the condition of stable stratification,

${ }_{25} \quad N=\left(\frac{g}{\rho} \frac{\partial \rho}{\partial z}\right)^{1 / 2}$
OSD

$10,55-81,2013$

Eddy measurements, coastal turbulence and statistics in the gulf of Lions

J. M. Redondo

\section{Title Page}

\section{4}

Back

Close

\section{Full Screen / Esc}

Printer-friendly Version

Interactive Discussion 
and also of the inertial frequency, given by the Coriolis parameter $f$, which is also reflected in the main Tidal component.

The Rossby deformation radius, which may be interpreted as the horizontal scale where Coriolis force is in equilibrium with buoyancy, limits the growth of the eddies 5 to scales of the order of $R d=N h / f$, where $h$ is the characteristic scale of the depth of the thermocline. If the scale of the vortices is greater than the calculated value of the $R_{\mathrm{D}}$, they are unstable and are broken in smaller ones, mostly because the excess angular momentum induced by the earth rotation may not be balanced by pressure due to buoyancy.

10 The local vorticity at small scale, $\omega(<5 \mathrm{~km})$ generated by the bathymetrical particularities of the sea bottom as well as the coastal friction seems to destabilize further the large vortices drifting South Westerly due to the Liguro-Provenzal current. The basic effect of Conservation of Potential Vorticity (Redondo and Platonov, 2001),

$q=\frac{f+\omega(x)}{H(x)}$

15 with $\omega(x)$ the local vorticity and $H$ the local depth and the slope of the thalwegs of the canyons also forces the eddies towards the cross-shore component $x$.

Estimating the magnitude of the maximum stable areas of the vortices during different seasons in the test area, we calculated the average values $\bar{\rho}, \partial \rho / \partial z, N$, as well as the maximum depth of the thermocline using the oceanographic data base Levitus, 20 that includes the temperature/salinity profiles of the NW Mediterranean Sea.

The results of the calculation of the average density, its vertical gradient, $N$ and $R_{\mathrm{D}}$ shows that there is a marked difference between Rossby deformation Radius in winter (March) and Summer (August), differences in density gradients between 0.0066 and $0.00388 \mathrm{~kg} \mathrm{~m}^{-4}$, leads to a theoretical difference in dominant sizes. of $6.2 \mathrm{~km}$. Between $256.2 \mathrm{~km}$ in winter and $18 \mathrm{~km}$ in summer. Other bathimetry and forcing effects give a wide distribution of sizes. The role of local vertical profiles of the density $\sigma_{\text {Stp }}\left[\sigma_{\text {Stp }}=\rho\right.$ $\left(\mathrm{kg} \mathrm{m}^{-3}\right)-1000$ ] have been calculated with the temperature and mean salinity, and

OSD

$10,55-81,2013$

Eddy measurements, coastal turbulence and statistics in the gulf of Lions

J. M. Redondo

Title Page

Abstract Introduction

Conclusions

Tables References

Figures

14

4

Back

Close

Printer-friendly Version

Interactive Discussion 
comparing March and August 1994 measured at open sea in a point approximately located $100 \mathrm{~km}$ Southeast of Barcelona. The large difference in the vertical distribution of the density between the summer and winter seasons, has important dynamical consequences at the ocean surface i.e. during the summer the surface density is smaller 5 and its vertical gradient is greater than during winter. In these conditions the frequency $N$ of the vertical buoyant oscillations near the sea surface layer (and its thickness) are greater in summer; this effect makes the vortices more energetic and stable. The calculated values of the Rossby deformation radio $R_{\mathrm{D}}$ confirm the existence of the greater size stable eddies in summer than in winter. Other areas have slightly different $10 R_{\mathrm{D}}$ ranges, in particular the Rhone area agrees quite well with the observed sizes in Figs. 3 and 4.

The Rossby deformation radio $R_{\mathrm{D}}$ or the typical maximum size of the vortices in the study zone is of order of $20 \mathrm{~km}$, i.e. a maximum area of the stable vortices is near $300 \mathrm{~km}^{2}$. A value of diameter of the vortices detected in cruises near the Blanes sub15 marine canyon of $13 \mathrm{~km}$, and the statistical analysis of (Arnau, 2000) with thermal IR Satellite images confirms our conclusions.

If we suppose that the average surface gradient is linear $\partial \rho / \partial z=\Delta \rho / h$, we can relate the maximum size of the vortices to the depth and structure of the thermocline, we obtain

$20 \quad R_{\mathrm{D}}=\frac{g^{\frac{1}{2}}}{f} \cdot\left(\frac{\Delta \rho}{\bar{\rho}}\right)^{\frac{1}{2}} \cdot h^{\frac{1}{2}}$

So that if $f$ and the value of $\Delta \rho$ do not change much we can relate the Rossby deformation Radius just to the square root of the thermocline depth. We can calculate the value of the local constant $C(x, y)(C \cong 1900)$ near Barcelona during summer. If we express $h$ in meters and $R_{\mathrm{D}}$ in kilometers, we obtain a practical local slide ruler equation

${ }_{25} \quad R_{\mathrm{D}}(\mathrm{km})=1.9 \cdot \sqrt{h(\mathrm{~m})}$
OSD

10, 55-81, 2013

Eddy measurements, coastal turbulence and statistics in the gulf of Lions

J. M. Redondo

Title Page

Abstract Introduction

Conclusions References

Tables Figures

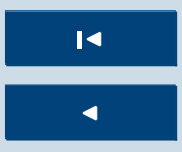

- I

Back

Close

Full Screen / Esc

Printer-friendly Version

Interactive Discussion 
this dependence that may be related to seasonal changes and to changes in the sea surface heat flux balance. Concerning the shape of the vortices detected in the coastal waters, between 1996 and 1998. Most of them (40\%) have an elliptical accused form and a the relation between the principal and secondary axis varied between values 5 of 1.25 and 1.5 (Fig. 6), that supports that the elliptical vortices are more stable that circular ones. In the case of the more general analysis of the all area of the Balearic Sea, this particularity is not so clear (Fig. 6).

The extension of most of the SAR detected vortices (63\%) is less than $100 \mathrm{~km}^{2}$. $33 \%$ of vortices occupy an area between 100 and $500 \mathrm{~km}^{2}$ and only $4 \%$ of the vortices 10 possess a large area between 500 and $1200 \mathrm{~km}^{2}$ (Fig. 3). About a $93 \%$ of vortices have a diameter less than $20 \mathrm{~km}$. Most of the vortices (79\%) have an ellipticity (relation between large and small diameter) near 1.12-1.63 indicating that this shape is more common, and more stable than a circle (Fig. 6).

In the present analysis of the 255 detected vortices, Fig. 7 shows that there is a 15 preferred orientation of the vortices is direction between NW and NE. Figure 8 shows the size distribution of these eddies.

The observed hyperbolic type of vortex distribution, is associated with Zipf's Law (Redondo and Platonov, 2009) and also indicates a turbulent type power law spectrum.

\section{Discusion}

20 Turbulent diffusion in the Ocean is important and directly related to the distribution of energy among the different scales, there is a range of different inertial type of scaling, but the main hypothesis of local equlibria invoked by Kolmogorov (1941) is not normally assured, and even less so in non-homogeneous coastal flows (Mahjoub et al., 1998; Redondo et al., 2008).

25 As mentioned above the evaluation of a certain turbulence time scale will give information on the persistence of a SAR detected feature in the ocean surface, which is also very important.
OSD

$10,55-81,2013$

Eddy measurements, coastal turbulence and statistics in the gulf of Lions

J. M. Redondo

\section{Title Page}

\section{4}

Back

\section{Full Screen / Esc}

Printer-friendly Version

Interactive Discussion 
It is also possible to analyse in a statistical integrated way all available frames in a region to characterize its mesoscale turbulence, for the NW Mediterranean. the probability of detection of the vortical slicks as a feature describing an eddy. The submarine canyon presence were shown to affect strongly the situation of the detected vortices 5 and their distribution of angles, shapes and size over the whole measurement period. There are several apparent relationships between the number of detected eddies and their size the area of the observed vertical slicks and the distance from Cape Begur following the Liguro-Provenzal current as shown by Redondo and Platonov (2001).

Relevant geometrical information of different areas is also given by the maximum 10 fractal dimension, which is related to the energy spectrum of the flow and its intermittency. Using all the available information it is possible to investigate the spatial variability of the horizontal eddy diffusivity $K(x, y)$. This information would be very important when trying to model numerically the behaviour in time of ocean pollution.

A simple method for evaluating the relevant meso-scale eddy diffusivity is straight 15 forward using dimensional analysis (as a velocity times a length scale) from the measured distribution of integral length scales and the eddy turnover times associated to inertial oscillations associated to the local Coriolis parameter (Redondo, 1994, 1996).

Many features have been identified with structures and phenomena observed in several experiments, and understanding of atmospheric and ocean dynamics has been significantly advanced. The experiments have provided new insights about the dynamics and have revealed a wide range of nonlinear behaviour. When the instability is caused by differential heating or by buoyancy there seems to be a range of very different dynamic regimes detected in the experiments, but not identified in the ocean. Work by Carrillo et al. $(2001,2008)$ has revealed the complex interactions possible between

lateral (or coastal) stirring and the rotating-stratified flow dynamics. The investigation of such strongly non-homogeneous flow that leads to intermittent two dimensional turbulence is believed very important if correct parametrizations of pollutant dispersion (such as oil spills) in coastal areas are to be made. The availability of a large scale flow allows both to measure Eulerian velocities with precision as well as Lagrangian flows
OSD

$10,55-81,2013$

Eddy measurements, coastal turbulence and statistics in the gulf of Lions

J. M. Redondo

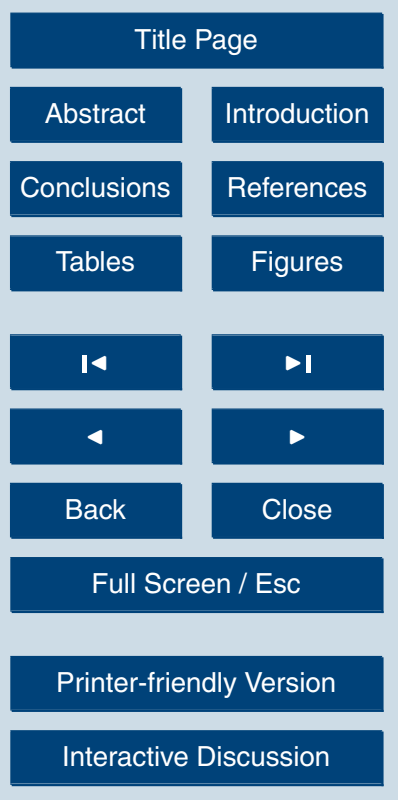


using particle tracking as well as local measurements of diffusivity by video recording the dispersion of neutral tracers. A possible oil spill prediction technique, involves the releasing of hundreds of small and inexpensive tracer (GPS) Lagrangian buoys near an accident to aid the predictions of coastal currents (Bracco et al., 2004; Redondo 5 and Platonov, 2009). Diffusion in the ocean exists on different space scales: from a molecular level (molecular viscosity and diffusion) to oceanic turbulent processes (from centimetres and metres vertical scale to tens and hundreds of kilometres of horizontal scale). After an initial Balistic phase, the non-lineal processes begin to dominant and new dynamic scales appear, the maximum concentrations of the pollutions $C_{\max }$ in the centre of surface patches on the Baltic Sea and in the Black Sea showed that $C_{\text {max }}$ is proportional to $t^{-3}$. The study of the turbulent diffusion is based on two methods. The first is Lagrangian (monitoring and numerical analysis of the motion of the particles or tracers) and the second one is Eulerian with a characterization of the spatial distribution of the velocities, correlations and energy spectral characteristics that may affect 15 locally the turbulent diffusion.

Using a systematic analysis of satellite images, there is a method of calculation of the average eddy diffusivity from a sequence of SAR images, using dimensional analysis and the local scales measured as integrals of the SAR reflectivity spatial correlations, here the local influences of the wind and the currents are important. Nevertheless, on the long run, horizontal directions will average out so using a single integral length scale defined in will be enough together with the inertial frequency. The method involving the multi-fractal dimension measurements is much more elaborated and seems to have a better theoretical justification, in the sense that it is possible that different concentrations showing different fractal dimensions may be due to different levels of intermittency and thus different spectra, which are not necessarily inertial nor in equilibrium.

We should be able to relate spatial topological features detected by SAR to the local diffusivity $K$, which depends on Waves, wind and local bathimetry as shown by Bezerra et al. (1998). Then reference plots of features such as the maximum fractal dimension with the integral of the fractal dimension over all possible intensity levels of SAR can

\section{OSD}

10, 55-81, 2013

Eddy measurements, coastal turbulence and statistics in the gulf of Lions

J. M. Redondo

Title Page

Abstract Introduction

Conclusions

Tables

References

Figures

14

$\rightarrow 1$

4

Back

Close

Printer-friendly Version

Interactive Discussion 
be used to predict the behaviour of the oil spills. Such curves $\langle D\rangle\left(T_{\text {oil }}\right)$ would grow monotonically in time and may give us information, taking account on the sea surface local weather, on how long ago was a particular oil spill released onto the sea. The topological structure may also help us to distinguish between oil seeps from the ocean 5 bottom (more distributed) and oil spills from ships (elongated) (Redondo and Platonov, 2009).

For example, the oil spill shown in Fig. 9, at a higher resolution using ASAR would correspond to a range of non- dimensional times $T_{\text {oil }}$ matching the fractal dimension of 1.3-1.4. There are other indications that may be useful from the SAR observations, 10 such as the low local wind at the time the image was taken. There is a consistent pattern that distinguishes the recent oil spills and the natural slicks that have adapted to the multi-scale turbulent flow of the ocean surface, of course the higher the resolution the easier to distinguish the type of oil spill or slick (Redondo and Platonov, 2009).

Recently, the new-design offshore oil resources detection methods have advanced 15 and with ERS-2/RADARSAT/ENVISAT SAR/ASAR imagery may offer a solution for locating oil rich reserves at the sea bottom due to the high incidence of the local detection of surface oil seeps traces of non-biological origin, which would be very useful in order to investigate new underwater oil deposits.

\section{Conclusions}

20 This work thus suggests that recent results on the dispersion and mixing properties of barotropic, vortex dominated flows are also relevant for understanding Lagrangian processes in baroclinic geophysical turbulence at a low Rossby number in the ocean.

When comparing different topological characteristics of the spatial features of a SAR image, we have to note that the information we have is the result of a dynamical com-

ple as tensioactivity, buoyancy, Langmuir cells, etc. From just the geometrical information
it is not possible in all cases to deduce the dynamics that lead to the observations.

\section{OSD}

$10,55-81,2013$

Eddy measurements, coastal turbulence and statistics in the gulf of Lions

J. M. Redondo

Title Page

Abstract Introduction

Conclusions

Tables

References

Figures

14

4

Back

Close

Printer-friendly Version

Interactive Discussion 
Nevertheless, we can make certain predictive conclusions comparing different surface features with diferent topology and here we will just comment a few examples:

- The strong vertical stratification of the surface water aids the development of the largest vortices. As the frequency $N$ strongly depends on the seasonal thermal balance, the wave mixing activity and other local bathimetry induced processes that affect the water column, the range and spatial distribution of detected vortices is thus very useful in the predictive behaviour of a marine zone. Seasonal data such as the difference between the surface and maximum density in pycnocline, and also its thickness (or depth) are the general factors that determine the kinetic energy of the vortices, as well as their size.

- The use of thematic maps that may be updated from combined satellite sensors and images and validated with space in situ observations may be even used to predict local diffusion. It is also important to couple satellite information and the multiscale information that may be used to inferr the small scale turbulent parametrizations needed to predict pollutant and tracer dispersion in the ocean surface. In such a manner, more sophisticated data analysis such as the evaluation of integral length scales or local fractal dimensions of the sea surface appearance, together with the detailed information of the position and sizes of the mesoscale dominant eddies of size about $R_{\mathrm{D}}$ provides useful information on the mesoscale ocean turbulence.

- The satellite-borne SAR and ASAR seems to be an excellent system not only to detect man-made oil spills and tensioactive slicks but it also detects dynamic features and the ocean eddies of different sizes. The study of the topology of the regions of different rugosity of the ocean can map the vortical, eliptical regions as well as the hyperbolic shear dominated areas, is also a convenient tool to investigate the eddy structures, the scale to scale energy and enstrophy transfer of a certain area, and to calculate the eddy diffusivity values. The effect of bathymetry and local currents are important in describing the ocean surface behaviour. In the

OSD

$10,55-81,2013$

Eddy measurements, coastal turbulence and statistics in the gulf of Lions

J. M. Redondo

Title Page

Abstract Introduction

Conclusions

Tables

References Figures

14

4

Back

Close

Printer-friendly Version

Interactive Discussion 
NW Mediterranean the maximum eddy size agrees remarkably well with the limit imposed by the local Rossby deformation radius using the usual thermocline induced stratification. The Rossby deformation radius, is attained when buoyancy and Coriolis forces are in equilibrium and the range of equilibrium values of $R d$ between 6 and $20 \mathrm{~km}$. Agree with most of the more stable vortices.

A geometry of gray scale ranges and boundaries of spatial dynamic surface features may contain new helpful information. Already we used multi-fractal analysis techniques to investigate man-made oil spills, Redondo and Platonov (2009), Redondo et al. (2008). It should help to apply these techniques to the analysis of ocean surface 10 multi-fractal features (eddies, mushroom-like currents, etc.) to understand the scale to scale transport (Redondo et al., 2008; Diez et al., 2008).

Acknowledgements. This work was supported by the Ministerio de Educación y Ciencia of Spain and the Universitat Politècnica de Catalunya (FTN-2001-2220, ESP2005-07551, RYC2003-005700) and from the European Space Agency. Authors also acknowledge the (ENV4-

15 CT96-0334) European Union Project and the ESA (AO-ID C1P.2240) for the SAR images provided.

\section{References}

Arnau, P. A.: Aspectos de la variabilidad de mesoescala de la circulacion marina en la plataforma continental catalana, Ph.D. thesis, Universitat Politecnica de Catalunya, UPC, 600 pp., 2000 (in Catalan).

Bezerra, M. O., Diez, M., Medeiros, C., Rodriguez, A., Bahia, E., Sanchez-Arcilla, A., and Redondo, J. M.: Study on the influence of waves on coastal diffusion using image analysis, Appl. Sci. Res., 59, 191-204, doi:10.1023/A:1001131304881, 1998.

Bracco, A., von Hardenberg, J., Provenzale, A., Weiss, J. B., and McWilliams, J. C.: doi:10.1103/PhysRevLett.92.084501, 2004.

OSD

$10,55-81,2013$

Eddy measurements, coastal turbulence and statistics in the gulf of Lions

J. M. Redondo

\section{Title Page}

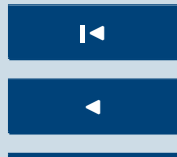

$>1$

\section{Full Screen / Esc}

Printer-friendly Version

Interactive Discussion 
Carrillo, A., Sanchez, M. A., Platonov, A., and Redondo, J. M.: Coastal and Interfacial Mixing. Laboratory Experiments and Satellite Observations, Phys. Chem. Earth Pt. B, 26, 305-311, doi:10.1016/S1464-1909(01)00011-9, 2001.

Carrillo, A., Redondo, J. M., Fraunie, P., and Durand, N.: Induced structures under seasonal flow conditions in the Ebro delta shelf. Laboratory and numerical models, II Nuovo Cimento C, 31, 771-790, 2008.

Davies, A. M., Xing, J., and Gjevik, B.: Barotropic and eddy generation by flow instability at the shelf edge: sensitivity to open boundary conditions inflow and diffusion, J. Geophys. Res., 108, 3035, doi:10.1029/2001JC001137, 2003.

10 Diez, M., Bezerra, M. O., Mosso, C., Castilla, R., and Redondo, J. M.: Experimental measurements and diffusion in harbor and coastal areas, II Nuovo Cimento C, 31, 843-859. 2008.

Flexas, M. M., Van Heijst, G. J. F., Jorda, G., and Sanchez-Arcilla, A.: Numerical simulation of barotropic jets over a sloping bottom: comparison to a laboratory model of the Northern Current, J. Geophys. Res., 109, C12039, doi:10.1029/2004JC002286, 2004.

15 Flexas, M. M., Van Heijst, G. J. F., and Trieling, R. R.: The behaviour of jet currents over a continental slope topography with a possible application to the Northern Current, J. Phys. Oceanogr., 35, 790-810, 2005.

Gade, M. and Redondo, J. M.: Marine pollution in European coastal waters monitored by the ERS-2 SAR: a comprehensive statistical analysis, IGARSS 99, Hamburg, vol. III(16371639), 308-312, 1999.

Hu, Z. H., Doglioli, A. M., Petrenko, A. A., Marsaleix, P., and Dekeyser, I.: Numerical simulations of eddies in the Gulf of Lion, Ocean Model., 28, 203-208, doi:10.1016/j.ocemod.2009.02.004, 2009.

Johannessen, J. A.: Coastal Observing Systems: The Role of Synthetic Aperture Radar, John Hopkins APL Technical Digest, 21, 41-48, 2000.

Jolly, G. W., Mangin, A., Cauneau, F., Calatuyud, M., Barale, V., Snaith, H. M., Rud, O., Ishii, M., Gade, M., Redondo, J. M., and Platonov, A.: The Clean Seas Project Final Report (ENV4CT96-0334), Ed. DG XII/D, Brusselas, 2000.

Kolmogorov, A. N.: Dissipation of energy in locally isotropic turbulence, C.R. Acad. Sci. USSR, 32, 16-18, 1941.

Mahjoub, O. B., Redondo, J. M., and Babiano, A.: Structure functions in complex flows, Appl. Sci. Res., 59, 299-313, 1998.
OSD

10, 55-81, 2013

Eddy measurements, coastal turbulence and statistics in the gulf of Lions

J. M. Redondo

\section{Title Page}

Abstract Introduction

Conclusions

References

Tables

Figures

14

4

Back

Close

Full Screen / Esc

Printer-friendly Version

Interactive Discussion 
Matulka, A., Redondo, J. M., and Carrillo, A.: Experiments in stratified and rotating decaying 2D flows, II Nuovo Cimento, 31, 757-770, 2008.

Munk, W., Armi, L., Fischer, K., and Zachariasen, F.: Spirals on the Sea, P. Roy. Soc. A-Math. Phy., 456, 1217-1280, 2000.

5 Platonov, A.: Application of the SAR images to the investigations of marine pollution and NW Mediterranean waters' dynamics, Ph.D. thesis, available at: http://www.tdx.cbuc.es, 2002 (in Spanish).

Redondo, J. M.: Turbulent mixing in the Atmosphere and Ocean, Fluid Physics, World Scientific, New York, 584-597, 1994.

10 Redondo, J. M.: Vertical microstructure and mixing in stratified flows, in: Advances in Turbulence VI, edited by: Gavrilakis, S., Machiels, L., and Monkewitzel, P. A., Kluwer Academic Publishers, 605-608, 1996.

Redondo, J. M. and Cantalapiedra, I. R.: Mixing in horizontally heterogeneous flows", Appl. Sci. Res., 51, 217-222, doi:10.1007/BF01082540, 1993.

15 Redondo, J. M. and Platonov, A. K.: Aplicación de las imágenes SAR en el estudio de la dinámica de las aguas y de la polución del mar Mediterráneo cerca de Barcelona, Ingeniería del Agua, 8, 15-23, 2001 (in Spanish).

Redondo, J. M. and Platonov, A.: Self-similar distribution of oil spills in European coastal waters, Environ. Res. Lett., 4, 14008, doi:10.1088/1748-9326/4/1/014008, 2009.

20 Redondo, J. M., Grau, J., Platonov, A., and Garzon, G.: Analisis multifractal de procesos autosimilares, Imagenes de satelite e inestabilidades baroclinas, Rev. Int. Met. Num. Calc. Dis. Ing., 24, 25-48, 2008 (in Spanish).

Reffray, G., Fraunié, P., and Marsaleix, P.: Secondary flows induced by wind forcing in the Rhone region of freshwater influence, Ocean Dynam., 54, 179-196, doi:10.1007/s10236-003-0079$25 \quad \mathrm{y}, 2004$.

Schaeffer, A., Molcard, A., Forget, P., Fraunié, P., and Garreau, P.: Generation mechanisms of sub-mesoscale eddy in the Gulf of Lions: radar observations and modelling, J. Geophys. Res., 61, 1587-1609, 2010.

OSD

$10,55-81,2013$

Eddy measurements, coastal turbulence and statistics in the gulf of Lions

J. M. Redondo

Title Page

Abstract

Introduction

Conclusions

References

Tables

Figures

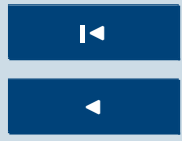

$>1$

Back

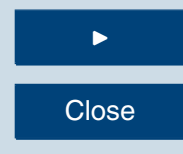

Full Screen / Esc

Printer-friendly Version

Interactive Discussion 


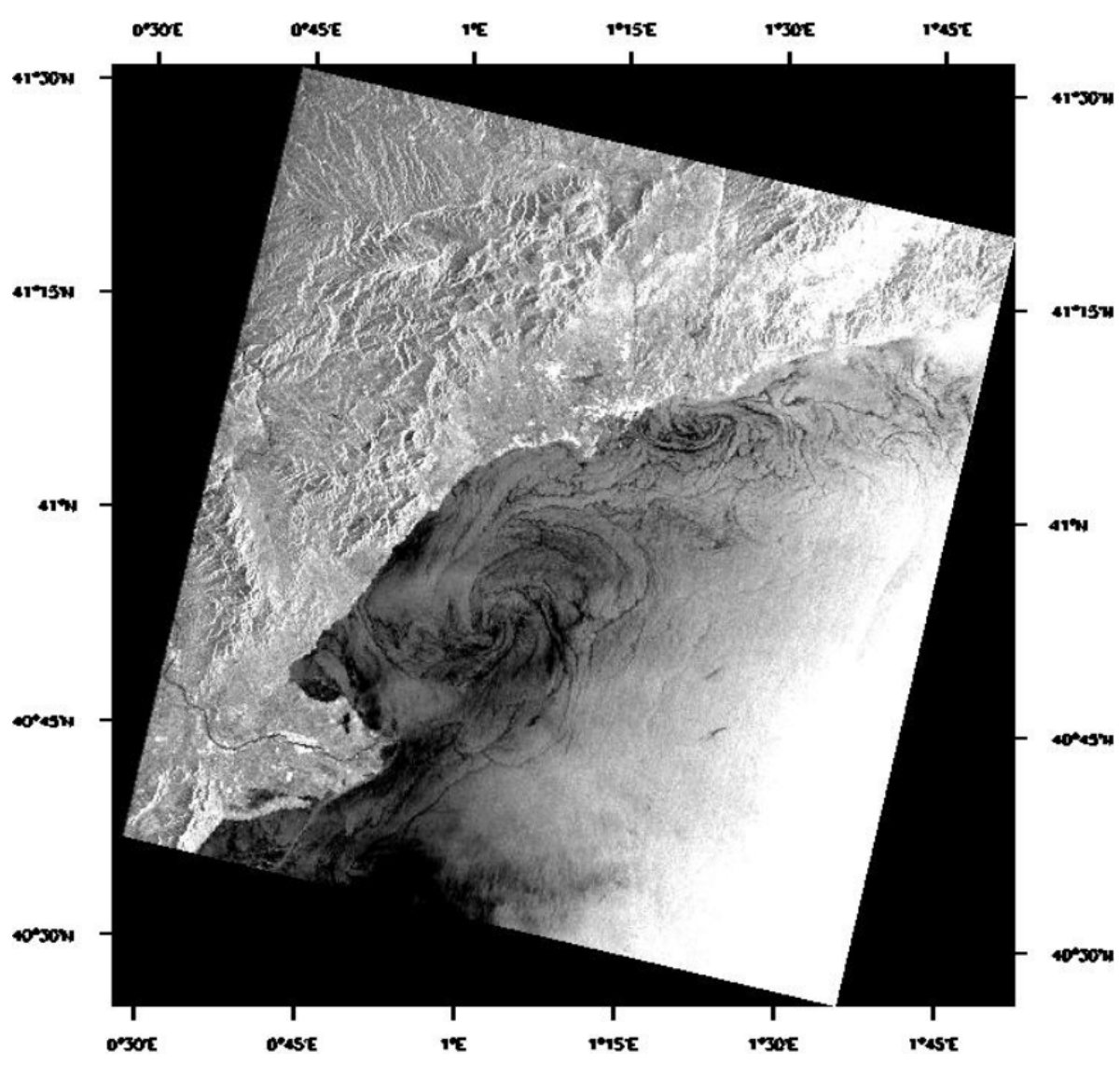

Fig. 1. Detection of eddies in the NW Mediterranean by SAR (ERS-1/2) Dynamic features on sea surface near the Ebro delta. ERS-2 SAR $100 \mathrm{~km} \times 100 \mathrm{~km}$ image on 27 August 1997 at 10:30 UTC.

\section{OSD}

$10,55-81,2013$

Eddy measurements, coastal turbulence and statistics in the gulf of Lions

J. M. Redondo

Title Page

Abstract

Introduction

Conclusions

References

Tables

Figures

14

4

Back

Full Screen / Esc

Printer-friendly Version

Interactive Discussion 


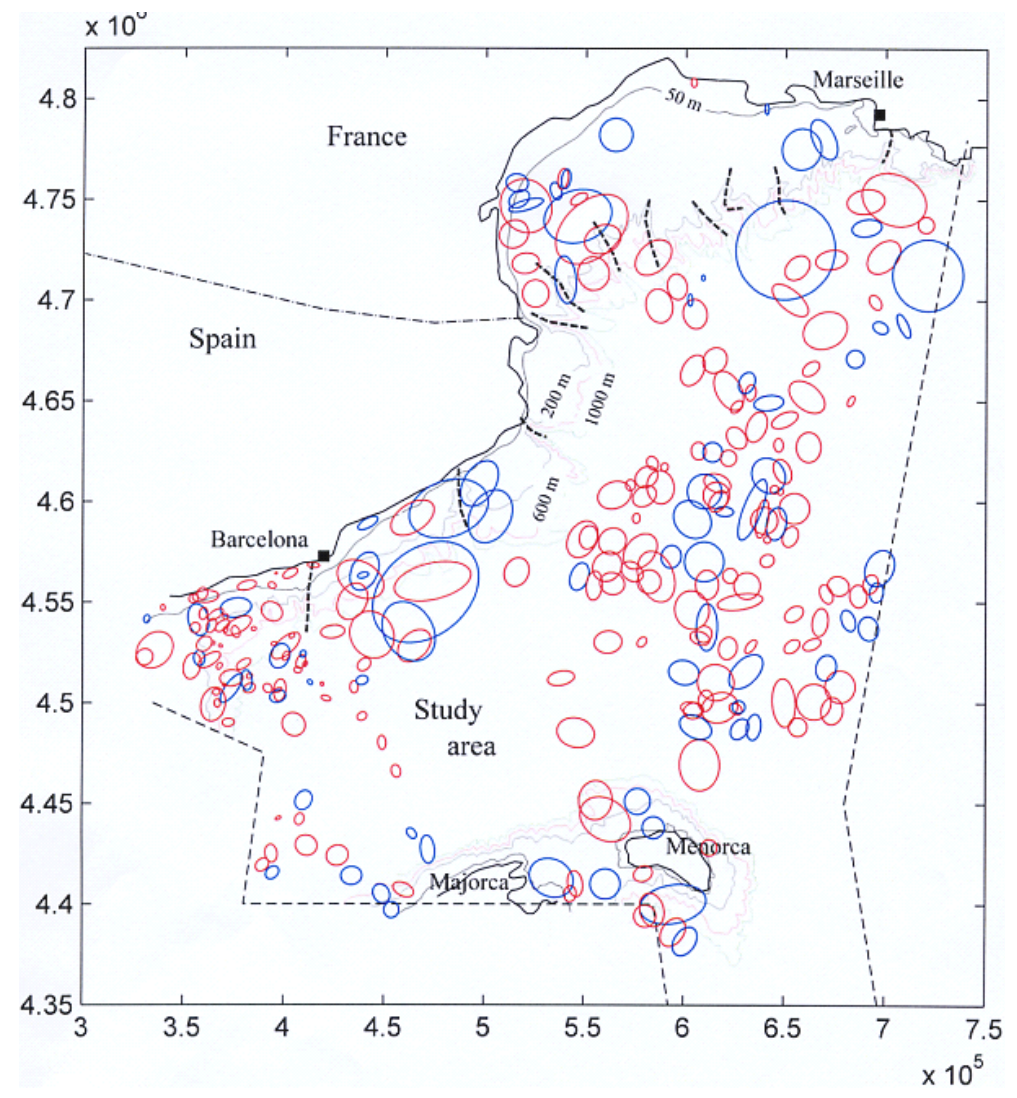

OSD

10, 55-81, 2013

Eddy measurements, coastal turbulence and statistics in the gulf of Lions

J. M. Redondo

Title Page

Abstract

Introduction

Conclusions

References

Tables

Figures

14

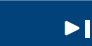

4

Back

Close

Full Screen / Esc

Fig. 2. Submarine canyons and the detected vortices in the period between 1996 and 1998 in the NW Mediterranean.

Printer-friendly Version

Interactive Discussion 

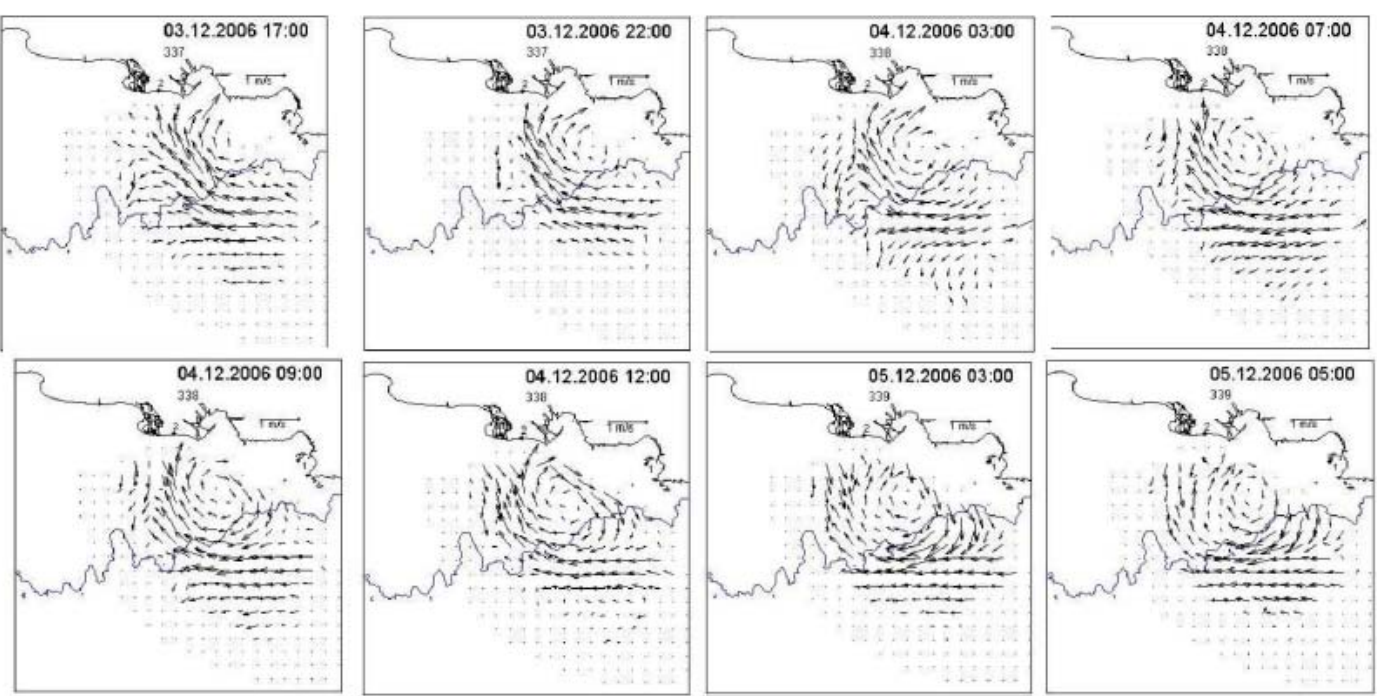

OSD

$10,55-81,2013$

Eddy measurements, coastal turbulence and statistics in the gulf of Lions

J. M. Redondo

Title Page

Abstract

Introduction

Conclusions

References

Tables

Figures

14

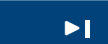

Fig. 3. A sequence of vortex formation during winter 2006 .

Back

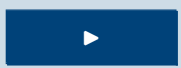

Full Screen / Esc

Printer-friendly Version

Interactive Discussion 

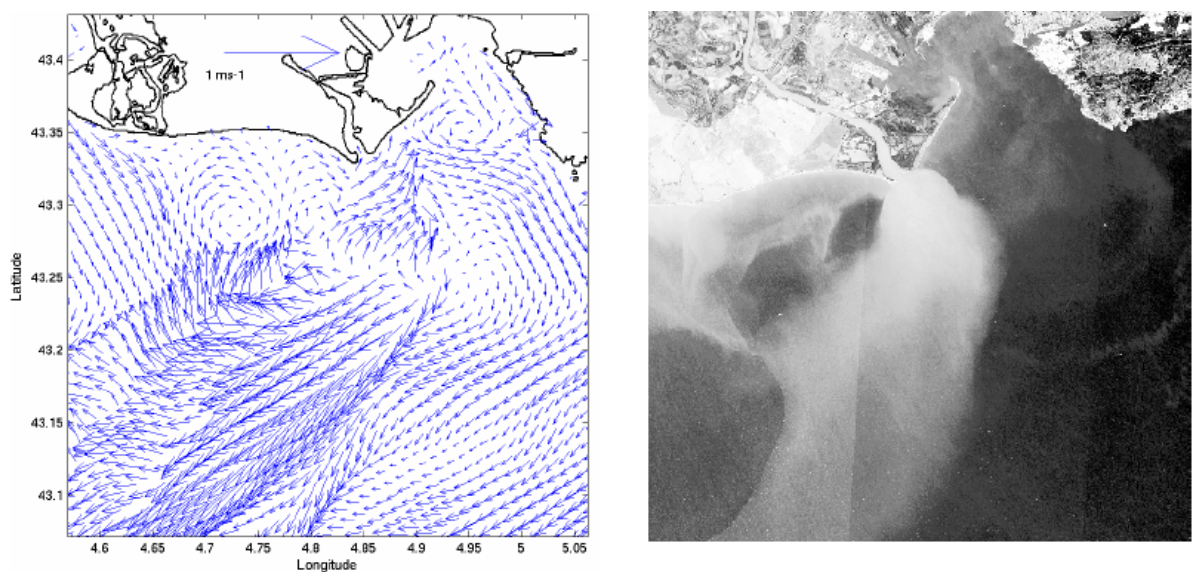

Fig. 4. Vortex formation in the Rhone river Freshwater influence region during high river flow (Reffay et al., 2004).
OSD

$10,55-81,2013$

Eddy measurements, coastal turbulence and statistics in the gulf of Lions

J. M. Redondo

Title Page

Abstract

Introduction

Conclusions

References

Tables

Figures

14

$>1$

Back

Close

Full Screen / Esc

Printer-friendly Version

Interactive Discussion 


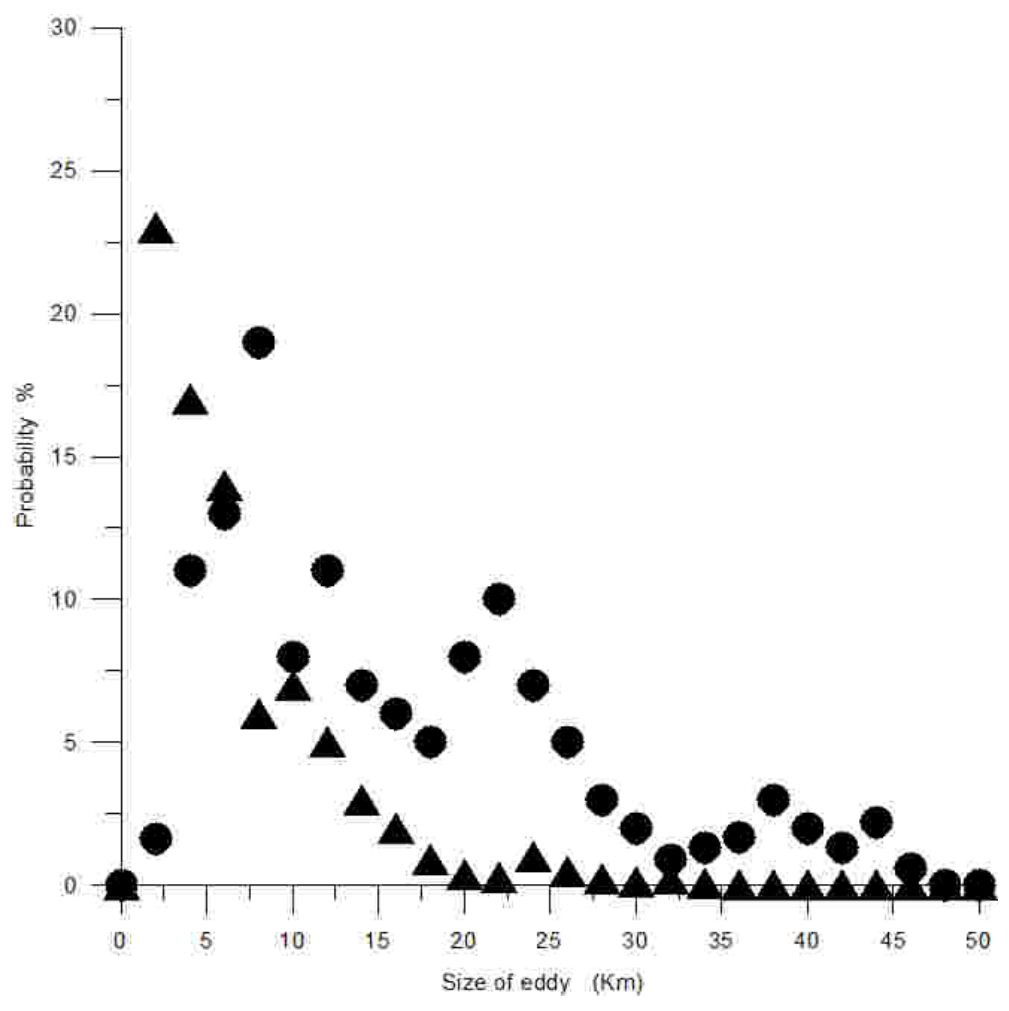

Fig. 5. Histogram of the percentage of detected vortices versus their diameter. Circles indicate the statistics of the area near Barcelona, while triangles indicate the results in all the Gulf of Lions.
OSD

$10,55-81,2013$

Eddy measurements, coastal turbulence and statistics in the gulf of Lions

J. M. Redondo

Title Page

Abstract Introduction

Conclusions

References

Tables

Figures

14

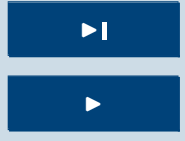

Back

Close

Full Screen / Esc

Printer-friendly Version

Interactive Discussion 


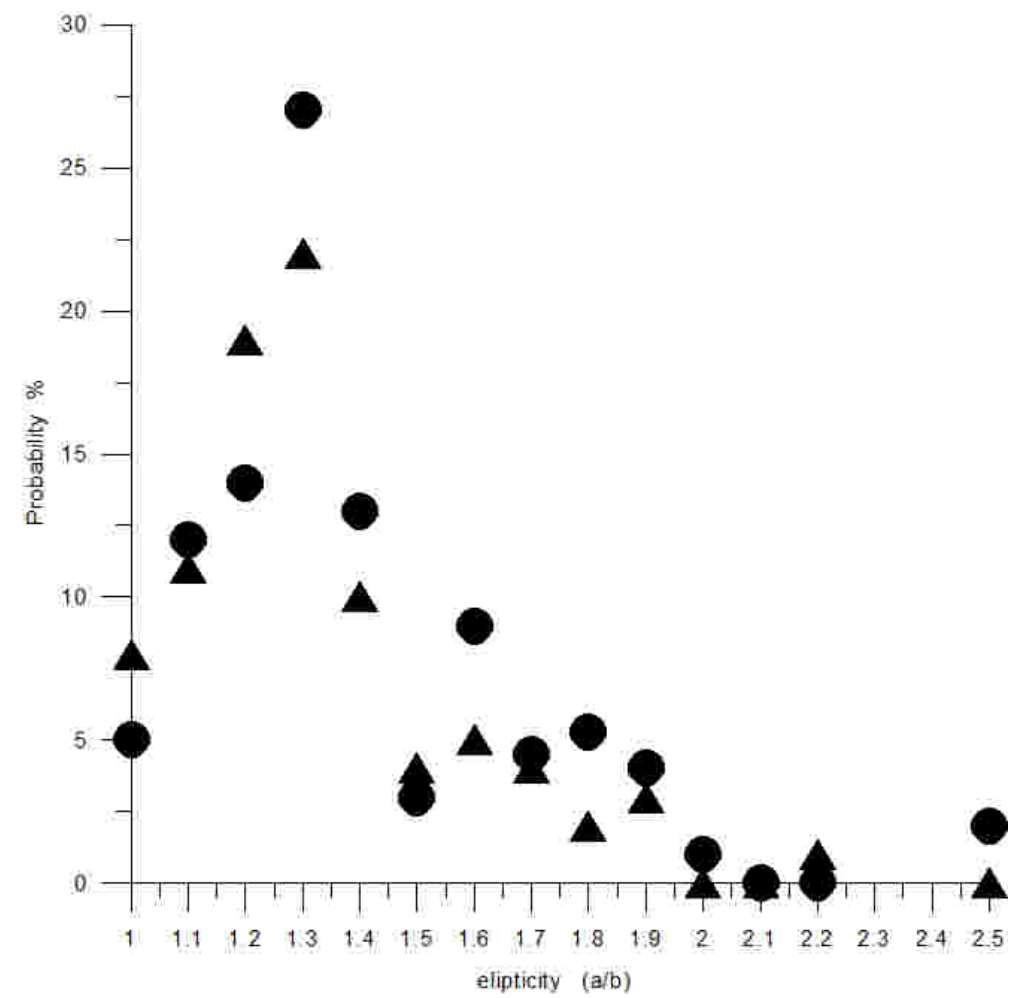

Fig. 6. Anisotropy distribution for the whole Gulf of Lions area (triangles) and for the coastal region between Cape Begur and the Ebro delta (circles).
OSD

$10,55-81,2013$

Eddy measurements, coastal turbulence and statistics in the gulf of Lions

J. M. Redondo

Title Page

Abstract

Introduction

Conclusions

References

Tables

Figures

14

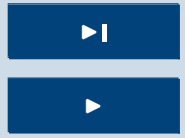

Back

Close

Full Screen / Esc

Printer-friendly Version

Interactive Discussion 


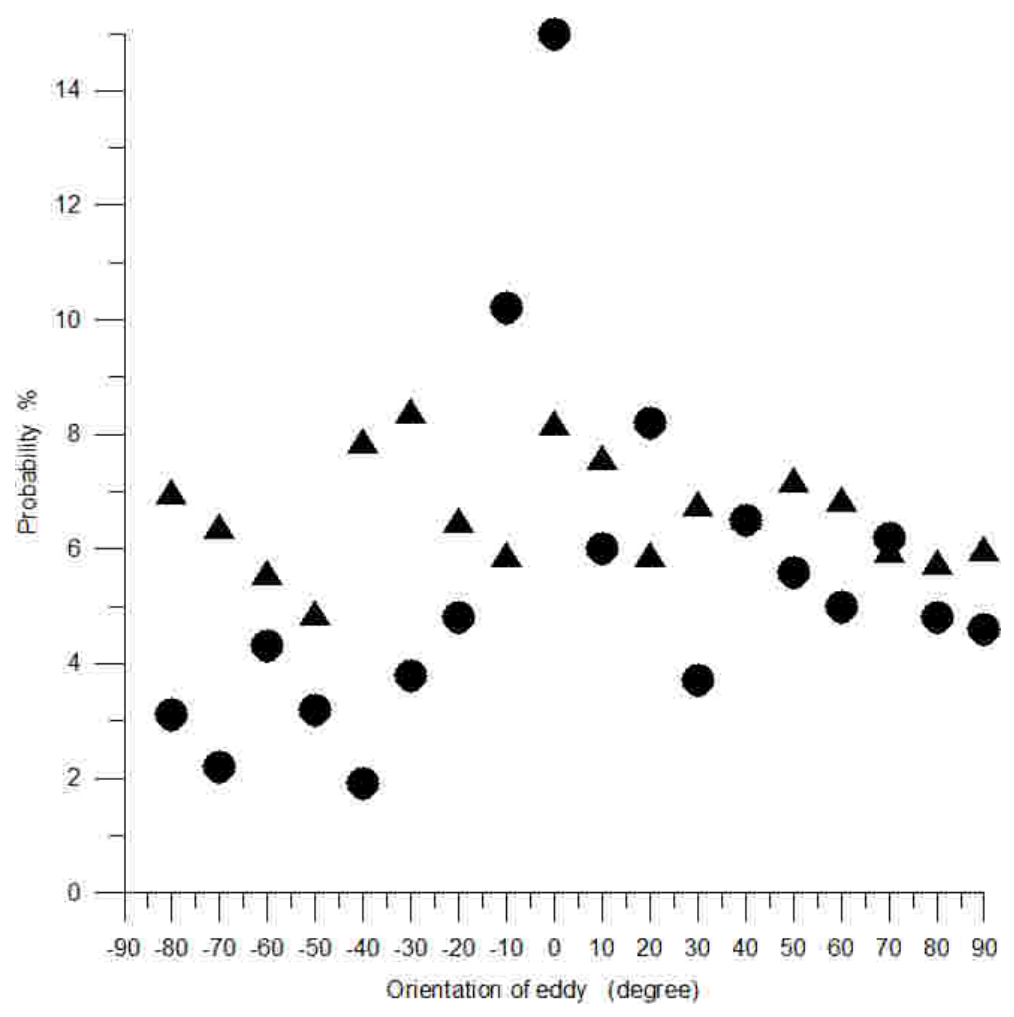

Fig. 7. Histogram of the vortices as a function of the angles (between the North and the direction of their greater axis; clockwise direction is positive). Circles indicate the coastal region near Barcelona (Begur-Ebro delta) and triangles correspond to the larger Gulf of Lions area.
OSD

$10,55-81,2013$

Eddy measurements, coastal turbulence and statistics in the gulf of Lions

J. M. Redondo

Title Page

Abstract Introduction

Conclusions

References

Tables

Figures

14

4

Back

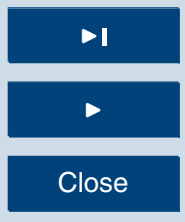

Full Screen / Esc

Printer-friendly Version

Interactive Discussion 
OSD

$10,55-81,2013$

Eddy measurements, coastal turbulence and statistics in the gulf of Lions

J. M. Redondo

Title Page

Abstract

Introduction

Conclusions

References

Tables

Figures

o
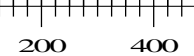

600

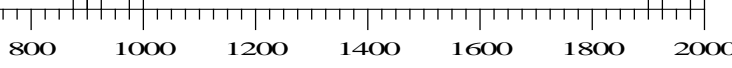

Fig. 8. Histogram of the detected vortices in function of their areas.

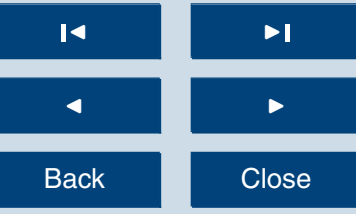

Full Screen / Esc

Printer-friendly Version

Interactive Discussion 


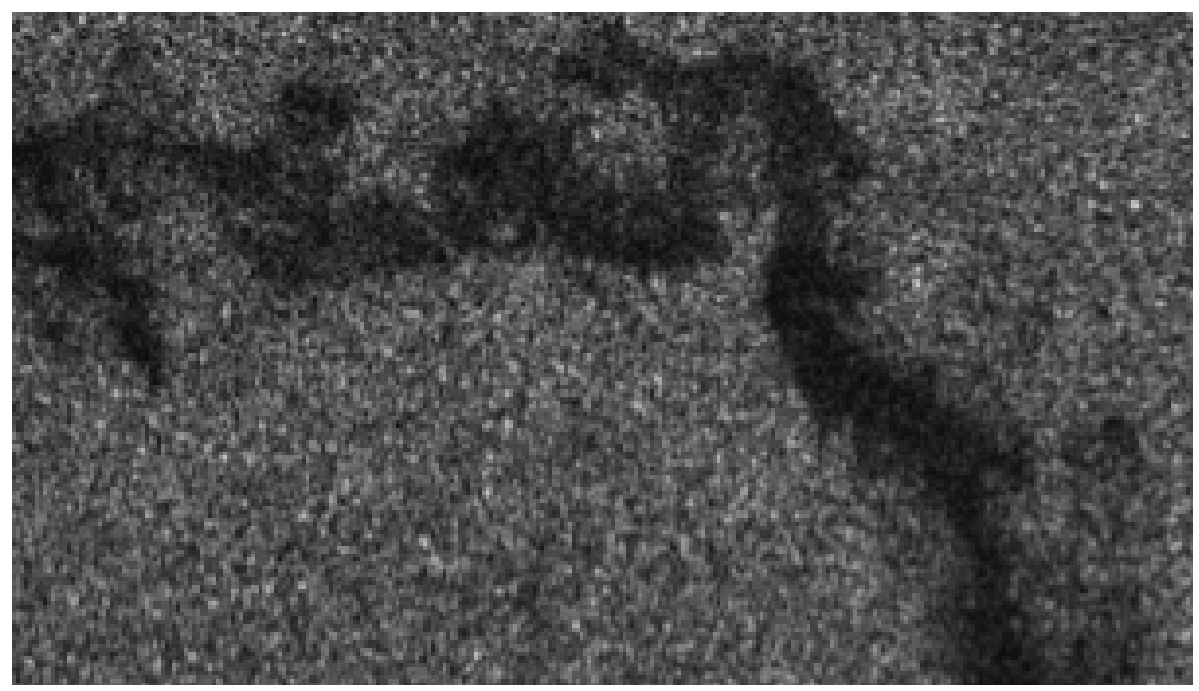

\section{OSD}

10, 55-81, 2013

Eddy measurements, coastal turbulence and statistics in the gulf of Lions

J. M. Redondo

Title Page

Abstract

Conclusions

\section{Tables}

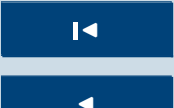

Back

Introduction

References

Figures

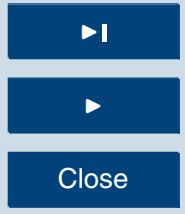

Full Screen / Esc

Printer-friendly Version

Interactive Discussion 